International Journal of Child, Youth and Family Studies (2020) 11(1): 23-45

DOI: $10.18357 /$ ijcyfs111202019472

\title{
FACTORS THAT DIFFERENTIATE PREADOLESCENTS' PERCEPTION-CHANGE OF PARENTAL LEGITIMACY
}

\author{
Laura C. Edwards, Herbert Rodrigues, and Kendra J. Thomas
}

\begin{abstract}
Whether preadolescents perceive their parents' authority as legitimate or not depends, in part, on the concerns and issues that they have dealt with before and during their preadolescence. Utilizing data from the first and second waves of the São Paulo Legal Socialization Study (SPLSS), we conducted one-way MANOVAs to analyze the role of procedural justice and the impact of victimization on preadolescents' perceptions of parental legitimacy across domains. Preadolescents were split into four distinct groups based on their perceptions of parental legitimacy and whether the perception shifted across the two waves of data. The study revealed a significant difference across groups in terms of procedural justice and on preadolescents' reported victimization levels. The latter indicate that suffering some form of victimization may have resulted in delegitimizing parental authority. The findings broaden the literature on parenting practices in preadolescence and make salient an emerging field of victimization impacting parental legitimacy.
\end{abstract}

Keywords: parental legitimacy, victimization, social legalization, procedural justice, preadolescence, parental authority

Laura C. Edwards EdD (the corresponding author) is an Assistant Professor of Psychology at Taylor University. 236 W. Reade Ave., Upland, IN 46989. Email: $\underline{\text { redwards@ @aylor.edu }}$

Herbert Rodrigues $\mathrm{PhD}$ is an Adjunct Professor in the Department of Sociology and Anthropology at Missouri State University, 901 S. National Ave., Springfield, MO 65897. He is also an associate researcher at the Center for the Study of Violence at the University of São Paulo (NEV/USP). Email: HRodrigues@MissouriState.edu

Kendra J. Thomas $\mathrm{PhD}$ is an Assistant Professor of Psychology at the University of Indianapolis, 1400 E. Hanna Ave., Indianapolis, IN 46227. Email: thomaskj@uindy.edu 
International Journal of Child, Youth and Family Studies (2020) 11(1): 23-45

Why do teenagers observe or break curfews? Why do some defer to or protest against authorities? Some would argue that the answer is related to whether youth bestow "legitimacy" upon authorities, be they primary caretakers, institutions, or law enforcers (Tyler, 2006). It has been suggested that recognition of legitimacy or its lack informs the choices that children, adolescents, and adults make to comply or not with norms and rules (Rodrigues \& Gomes, 2017; Thomas et al., 2018; Trinkner et al., 2012). While there are documented and expected reasons for a decline in parental legitimacy (PL) in areas of personal domain such as choosing friends or what clothes to wear (Darling et al., 2008), there are individual factors that need to be further investigated, such as the role victimization plays in PL (Medina \& Rodrigues, 2019).

The importance of understanding PL has captured increased scholarly attention by psychologists, sociologists, and criminologists (e.g., Pennington, 2015; Tyler \& Trinkner, 2017). For this inquiry, we adopted Tom Tyler's definition of legitimacy used in several works (Fagan \& Tyler, 2005; Sunshine \& Tyler, 2003; Tyler, 2003, 2006, 2011; Tyler et al., 2014). He posited that legitimacy is the accepted right to rule, and the recognition of that power and of the duty to obey; legitimacy depends on a psychological property of an individual, one that leads to perceiving another's authority as appropriate, proper, and just (Tyler, 2006). In his seminal book, Tyler (2006) explained that trust placed in the authority figure and perceived obligation to obey are two fundamental determinants in granting PL. The legitimacy of parental authority is a multifaceted construct and occurs within the developmental context. Legitimacy granted to those in authority initially develops in childhood, becomes more complicated during adolescence (Tapp, 1991; Tyler \& Trinkner, 2017), and is influenced by multiple variables: family, school, neighborhood, and juvenile justice (Darling et al., 2008; Fagan \& Tyler, 2005; Thomas et al., 2018; Tyler \& Trinkner, 2017). Several of these variables are delineated in Urie Bronfenbrenner's (1977) ecological theory, in which he asserted that not only the immediate settings of family, school, and peers (what he termed the microsystem), and their interrelations (the mesosystem), but also the changing relations between an individual and such environments as social structures, media, and the legal system (the exosystem) impinge upon and impact development.

More recently, inquiries into how people acquire beliefs and attitudes about parental authorities have been the focus of multiple studies that command the attention of multidisciplinary scholars worldwide (Darling et al., 2008; Darling et al., 2005; Smetana et al., 2000; Smetana et al., 1991; Thomas et al., 2018; Trinkner, Jackson, \& Tyler, 2017). A review of this literature revealed that central to the discourse of PL is legal socialization, generally defined as the process of acquiring dispositions and beliefs about the law, legal authorities, and legal institutions (Piquero et al., 2005; Trinkner et al., 2019), and that PL is often studied within the context of legal socialization (Tyler \& Trinkner, 2017).

The association between procedural justice, defined as the perception of whether authorities act reasonably and justly during dispute resolution, and legitimacy has received 
International Journal of Child, Youth and Family Studies (2020) 11(1): 23-45

significant attention (e.g., Darling et al., 2008; Trinkner et al., 2012). At the same time, research on how procedural justice and PL develop and decline within younger populations is still being established (Durkin, 2016). The present study accedes to the need for more research to be attentive to the familial domain (Trinkner \& Cohn, 2014) and highlights the factors that differentiate the preadolescents' PL perception-change that can happen during this stage of life. The study also investigates how victimization exposure differentiates the perception of parental authority. The focus on victimization emanated from an analysis of the existing literature that revealed extensive scrutiny of the relationship between victimization and psychological distress, subsequent offending, and clinical issues (Boney-McCoy \& Finkelhor, 1995; Chang et al., 2003; Flannery et al., 1998; Hamby et al., 2011; Mrug \& Windle, 2010; Nicholas \& Rasmussen, 2006; Shaffer \& Ruback, 2002; Wilson et al., 2009). Despite this plurality of inquiries, we could not find any empirical evidence regarding the impact of victimization on PL. Since direct and indirect victimization at home, at school, and in the community can negatively affect preadolescents (Hamby et al., 2011; Hughes et al., 2015; Johnson et al., 2002), both direct and indirect victimization are represented in this inquiry.

The research that we are reporting on here drew from a diverse sample collected from a cohort longitudinal study ( $n=800$, beginning at age 11) carried out in São Paulo, Brazil. The focus of our study was to understand whether procedural justice and victimization are essential variables in distinguishing PL perception-change in early adolescence. To examine this question, we divided preadolescents into legitimacy perception-change groups based on how their legitimacy attributions crossed the threshold that we calculated (see the Method section below) or remained the same from wave I to wave II. The anticipated groups were those who had lower PL perceptions in both waves, those whose measures of PL perceptions declined from wave I to wave II, and those who had high PL perceptions in both waves.

\section{Procedural Justice in a Younger Population}

Tyler and Trinkner (2017) explained procedural justice as the judgement made regarding whether those in authority make decisions fairly during interactions and whether all voices are given an opportunity to be heard. According to an earlier study conducted by Tyler (2003), procedural justice is linked with legitimacy as it emerges from the perceived fairness of both the enforced procedures and the outcome. Developmentally, an understanding of procedural justice begins to form in childhood, is shaped during adolescence, and is influenced by interactions with authority figures; this understanding also influences both moral development and delinquent behavior, and has a long-lasting effect (Fagan \& Tyler, 2005; Trinkner \& Cohn, 2014; Trinkner et al. 2019). Thus, it is critical to understand which factors differentiate the rise or decline in PL in preadolescence.

Since there is a call for more inquiries into procedural justice that involve preadolescents (Durkin, 2016; Trinkner \& Cohn, 2014), the focus of this article is on procedural justice research that was conducted with younger populations. Early research on procedural justice found that 
International Journal of Child, Youth and Family Studies (2020) 11(1): 23-45

elementary school students recognized the unfairness of outcomes when procedural fairmindedness was violated (Gold et al., 1984). Almost ten years later, Hicks and Lawrence (1993), using hypothetical scenarios, developed a scale to measure the importance of procedural justice in the minds of seventh and ninth graders and found that teens consider procedural justice essential. Even in preadolescence, the notions of respect, neutrality, fairness, and the desire to feel heard and validated underlie young people's understanding of procedural justice (Cashmore, 2002). More recently, Durkin's (2016) research corroborated both Gold et al.'s (1984) and Hicks and Laurence's (1993) findings, adding that even younger children (ages 4-8) robustly preferred methods that are procedurally just. Being cognizant of factors that differentiate the preadolescents' perception-change of PL is important, given its influence on compliance and on legitimacy transference, or lack thereof, to other authority figures (Fagan \& Tyler, 2005).

\section{Procedural Justice and Parental Legitimacy}

The extant literature on PL has examined variables such as parenting styles, and autonomy domains such as personal, prudential (safety-related issues), and moral development (Darling et al., 2007; Darling et al., 2005; Smetana \& Daddis, 2002; Smetana \& Metzger, 2005). Scholars have also investigated premature rejection of parental authority beliefs (Kerr et al., 1999) and resistance to parental authority over what adolescents perceived as personal decisions (Smetana et al., 2005). In addition, researchers have investigated PL connection to teens' drug usage, which revealed the adolescents' belief that drug usage is a personal issue rather than a prudential one (Benchaya et al., 2011; Milnitsky-Sapiro et al., 2006, Nucci et al., 1991; Tisak et al., 1994).

\section{Victimization}

As evidenced by research (Boney-McCoy \& Finkelhor, 1995; Chang et al., 2003; Hughes et al., 2015; Medina \& Rodrigues, 2019; Shaffer \& Ruback, 2002; Sharkey et al., 2012), there has been a historical focus on understanding the relationship between victimization, maltreatment, and child abuse with maladaptive behavior. With this background in mind, victimization in our study was examined in three areas: home, school, and neighborhood, and included a focus on a range of behaviors by the perpetrator that encompassed treating others cruelly and unfairly (see specific questions under "Measures" in the Method section below) and considered both direct and indirect impact.

Home: The research we reviewed showed a robust connection between home victimization and preadolescents coping strategies, psychological trauma symptoms, and antisocial and violent behavior (Finkelhor \& Dzuiba-Leatherman, 1994; Finkelhor et al., 2005; Flannery et al., 1998; Hartinger-Saunders et al., 2011; Turner et al., 2012; Wilson et al., 2009). In addition, Dishion and McMahon (1998) provided an empirical rationale for utilizing parental monitoring of children's whereabouts as a protective factor against victimization in high-risk settings as a way to prevent adolescent problem behavior. In terms of long-term clinical impacts of victimization, Nicholas and Rasmussen (2006), who focused on children who grew up witnessing parental violence, revealed that abuse and victimization significantly predicted depression and aggression. Subsequent studies 
International Journal of Child, Youth and Family Studies (2020) 11(1): 23-45

confirmed these findings and added the presence of behavioral problems in early adolescence to this list of impacts (Mrug \& Windle, 2010). Other studies revealed that vicarious victimization (e.g., witnessing someone being victimized) could be distressing to preadolescents (Johnson et al., 2002; Moffitt \& Caspi, 1998; Nofziger \& Kurtz, 2005; Rodrigues \& Gomes, 2017; Rosenbaum et al., 2005). Overall, it has been established that victimization has multiple adverse effects, such as later delinquencies and substance abuse (Aquilino \& Supple, 2001). Victimization is also an early predictor of conduct problems (Chang \& Shaw, 2015). Notwithstanding these findings, the literature has not undertaken research on how direct or indirect home victimization informs the rise or decline of PL.

School: The consequences of student victimization have long-lasting ramifications. An inquiry with Brazilian students (de Albuquerque Williams et al., 2011) showed that $45 \%$ of students ages 11 to 14 experienced school victimization, and $45.3 \%$ experienced verbal violence. The study revealed that $89 \%$ of the victimized students reported anxiety, sadness, and loneliness, while $38 \%$ received a post-traumatic stress disorder diagnosis. Hughes and colleagues (2015), utilizing the 2011 National Youth Risk Behavior Survey of young people in the United States, revealed that students who experienced victimization were more likely to avoid school and school activities than non-victims. An analysis of the United States 2013 School Crime Supplement to the National Crime Victimization Survey conducted by the Bureau of Justice Statistics revealed that victims of crime and violence reported fearing harm at school at higher rates than non-victims (Lessne et al., 2016). Conspicuously, no research was found that studied the role of school or neighborhood victimization on PL.

Neighborhood: The focus on neighborhood victimization research has primarily been on its role as a precursor of the victim-offender cycle (Berg, 2011; Lauritsen \& Laub, 2007). According to Berg (2011), who studied the interplay of neighborhood conditions and victimization, "one of the most reliable predictors of violent victimization is violent offending" ( $p$. 13). Another focus of inquiry (in the form of violence exposure in poor neighborhoods) that has received notable attention is the focus on victimization's impact on cognitive problems, as well as the development of antisocial behavior in adolescents (Kliewer et al., 2001; Wilson et al., 2003). Additionally, Gibson (2012) sought to understand the influence of the neighborhood on violent victimization among children and adolescents. His research found a relationship between low selfcontrol and violent victimization risk. Apart from our inquiries, no research has yet investigated how neighborhood victimization alters PL. Such research is particularly relevant in societies with high rates of urban violence and insecurity.

Despite the diversity of research on home, school, and neighborhood victimization, there is a paucity of scientific evidence about the impact of direct and indirect victimization suffered by preadolescents on PL. Truman and Morgan (2016) reported figures from the Bureau of Justice Statistics' National Crime Victimization Survey for 2015, when 1.86\% of U.S. residents aged 12 or older experienced a violent victimization (about 5 million occurrences in all). Truman and Morgan's figures show that the rate of violent victimization has declined significantly since the 
International Journal of Child, Youth and Family Studies (2020) 11(1): 23-45

90s. Regrettably, victimization levels are still disturbingly high, indicating a need for more studies with a non-clinical and non-legal perspective. We have therefore undertaken this study.

\section{Method}

\section{Participants and Procedure}

The present study used data collected from the São Paulo Legal Socialization Study (SPLSS), a longitudinal panel developed to explore how preadolescents form their perceptions of rules and law, and how they legitimize authority figures. The SPLSS emphasizes the impact of individual experiences with legal and non-legal authorities (Center for the Study of Violence at the University of São Paulo, 2016/2017). The initial sample was drawn from the population of students enrolled in the sixth grade, who attended public and private schools in the city of São Paulo, Brazil. The SPLSS panel consists of 800 students (400 boys, 400 girls, age 11 years, born in 2005, 47\% White, 12\% Black, 27\% "Pardo" (mixed race), 9\% other, 7\% not specified), conducted by the Center for the Study of Violence at the University of São Paulo (NEV/USP).

Our research procedure was in two stages: the selection of schools and the selection of students. According to the Brazilian National School Census of 2014 (Instituto Nacional de Estudos e Pesquisas Educacionais Anisio Teixeira [INEP], 2014), 59\% of middle school students in the city of São Paulo are from public schools, and $41 \%$ are from private schools. In order to meet this proportion and also cover all regions of the city we employed the Probability Proportional to Size (PPS) method in our first stage, which resulted in 112 schools being selected (Skinner, 2016). According to the INEP 2014 census, this number covers the school distribution across the city.

In our second stage we hired the Brazilian Institute of Public Opinion and Statistics ${ }^{1}$ (IBOPE) to contact the students and collect the data. Therefore, after pre-tests and final review, IBOPE converted the survey questionnaire into the software, Survey-To-Go ${ }^{2}$, so the researchers performing the fieldwork could use tablets to conduct the interviews with students. Consent forms were obtained from parents of all students who were included in the study. All procedures involving students were in accordance with the ethical standards of Resolution 466/2012 (Brazilian National Health Council, 2013). The board of the local research institute, the School of Arts, Sciences and Humanities from the University of São Paulo, approved the study.

The first wave (2016) full sample included 800 participants, equally divided between boys and girls. The second wave (2017) sample consisted of 750 students $(50.13 \%$ female; $49.87 \%$ male, mean age 11.96 , attrition rate $6.5 \%$ ). The analysis presented here includes only those who completed both waves.

\footnotetext{
${ }^{1}$ http://www.ibope.com.br/

2 https://www.dooblo.net/products/
} 
International Journal of Child, Youth and Family Studies (2020) 11(1): 23-45

Our study investigated how interactions with different authority figures shape the beliefs, attitudes, and behaviors of preadolescents. In order to discuss preadolescents' perception of PL, we split participants into four groups (see "PL measurement and group classification" below): low PL perception in both waves, high PL perception in both waves, change in PL perception from high to low, and change in PL perception from low to high. The analysis sought to answer two research questions:

1. Do the four groups differentiate in parental procedural justice judgements in both the first and second waves?

2. Do the four groups differentiate in self-reported victimization levels in the areas of home, school, and neighborhood in both the first and second waves?

We hypothesized that parental procedural justice would positively differentiate perception-change toward legitimizing parents, while victimization would help distinguish the delegitimizing groups.

\section{Measures}

Victimization: Measurements of victimization for the SPLSS were based on children and youth victimization research and literature (Assis et al., 2013; Cardia, 2012; Finkelhor et al., 2005; Hamby et al., 2005). In order to measure victimization, the survey contained questions about family, school, and the neighborhood. All victimization items were measured on a four-point Likert scale ( $0=$ never; $1=$ once; $2=$ a few times; $3=$ many times $)$. The constructs were measured based on the sum of the items in their category (family, school, and neighborhood) in order to capture the cumulative effect of victimization. Note that in wave I the participants were asked if they had ever experienced such victimization. In wave II, they were asked if they had experienced these victimization events since the last questionnaire. Therefore, wave II results should be interpreted as recent victimization.

Family victimization: The same questions were asked in both waves: "Have you seen fights and arguments between adults in your family/home?"; "Has a peer at home slapped, punched, kicked, or hit you with an object?"; and "Has an adult at home slapped, punched, kicked, or hit you with an object?"

School victimization: The same questions were asked in both waves: "Have you seen students fighting each other at school?"; "Has another student slapped, punched, kicked, or hit you with an object?"; "Has an adult at school slapped, punched, kicked, or hit you with an object?"; and "Has anyone stolen something from you at school?"

Neighborhood victimization: Participants were asked if they have seen people in their neighborhood selling drugs on the street, being robbed, or carrying guns (without being a policeman), or if they have ever heard a gunshot in their neighborhood. These items were asked in both waves. 
International Journal of Child, Youth and Family Studies (2020) 11(1): 23-45

Procedural justice: The measurements of procedural justice were based on prior legal socialization studies (Fagan \& Tyler, 2005; Trinkner \& Cohn, 2014; Tyler, 2011; Tyler \& Blader, 2003). In both waves, participants answered questions about what they believed would happen if their parents found out they did something wrong (e.g., "Would they give you the opportunity to express your side of the story?", "Would they listen to all sides of the story, before making any decision?", and "Would they talk to you politely?"). These questions cover essential dimensions of procedural justice such as voice, neutrality, and respect (Blader \& Tyler, 2003; Tyler, 2006). The Cronbach's alpha was poor in the first wave (0.52) but increased to an acceptable level in the second wave (0.65). An exploratory factor analysis was conducted on these questions, and they all loaded on the same factor utilizing a maximum likelihood extraction method and a varimax rotation (loading > .35). Due to the theoretical grounding of the questions, and the results of the factor analysis, both years of data were interpreted, but caution should be used interpreting the first wave due to the low internal reliability.

PL measurement and group classification: Participants were asked if their parents were legitimate sources of authority on 10 issues (see Table 1). The measurements of PL were based on legal socialization and psychological studies (Darling et al., 2007; Darling et al., 2008; Fagan \& Tyler, 2005; Jackson et al., 2012; Trinkner \& Cohn, 2014). The measures took into consideration the developmental and cultural context of Brazilian reality (Rodrigues et al., 2017). For this reason, the first wave of data is mostly dichotomous questions (yes/no) due to students' low literacy rates and difficult in understanding the Likert scales, particularly in the poorest areas of the city. The second wave was assessed on a four-point scale (strongly disagree to strongly agree) because participants were older, and researchers believed they would be able to grasp a more complex scale. However, for the longitudinal comparison, the second wave measures were dichotomized with strongly disagree and disagree, indicating "not legitimate" and strongly agree and agree indicating "legitimate". These 10 areas were averaged in order to establish an overall PL score for each participant at each time point. An averaged score of 1.00 indicates they believed their parents were legitimate sources of authority in all areas. The average was used instead of the sum because participants only had to answer a question if their parents had a rule in that area. Utilizing the average ensured that participants' PL beliefs were not underrated if they did not answer the question. For example, if a participant only answered 8 out of 10 items (because their parents only had eight of the rules), but they believed their parents were legitimate on all of the rules, they would still have a 1.00 average and be in the high PL classification.

The upper bound for attributing low PL was an averaged score of 0.80 out of 1.00 . This cut-off was based on the frequencies of the variables, selecting roughly the lowest $20 \%(24.50 \%$ in the first wave and $18.10 \%$ in the second wave). This cut-off indicates that the participants in the "low" groups had identified at least two areas where their parents had rules to which the participants did not attribute legitimacy. 
International Journal of Child, Youth and Family Studies (2020) 11(1): 23-45

Participants were divided into four groups based on how their PL attributions crossed the threshold or remained the same from wave I to wave II:

- High-High: In both wave I and wave II, participants attributed legitimacy to 9 or 10 areas (out of $10 ; n=481$ ).

- Low-Low: In both wave I and wave II, participants' averaged scores were below the cutoff $(n=55)$.

- Low-High: In wave I, participants' averaged scores were below the cut-off; in wave II they were above $(n=127)$.

- High-Low: In wave I, participants' averaged scores were above the cut-off; in wave II they were below $(n=79)$.

Table 1. Percentage of Participants Who Answered "Yes” on PL for Each Domain

\begin{tabular}{lcc}
\hline PL issue & Wave I & Wave II \\
\hline Clean your room & 94.20 & 96.70 \\
Control curfew, homework & 94.20 & 92.40 \\
Control media & 90.00 & 90.10 \\
Fight with siblings* & 89.90 & 93.40 \\
Play in the streets & 74.70 & 86.30 \\
Tell the truth & 97.60 & 98.50 \\
Cuss words & 97.70 & 96.80 \\
Dating & 70.80 & 79.80 \\
Drink/smoke & 99.10 & 99.30 \\
Control who you hang out with & 93.10 & 93.60 \\
\hline
\end{tabular}

Note. *Included only participants with siblings $(n=612)$.

\section{Procedural Justice}

One-way MANOVAs were conducted on both waves of data to see if there were differences in parental procedural justice across the four groups from wave I to wave II. These analyses showed a significant difference for procedural justice: $F(3,738)=5.023, p<.01, \eta^{2}=$ .020. A follow-up pairwise comparison with a Bonferroni correction revealed that in wave I, parental $\eta^{2}$ procedural justice was significantly higher in the High-High group than in the LowLow and the High-Low group. For wave II, parental procedural justice was significantly lower in the Low-Low group than in the High-High and the High-Low groups. See Table 2 for descriptive statistics.

A discriminant analysis was conducted as a follow-up procedure to understand which variable contributed the most to the differences between groups. The analysis revealed that procedural justice contributed more in wave II $(r=.888)$ than in wave I $(r=.607)$. 
International Journal of Child, Youth and Family Studies (2020) 11(1): 23-45

Table 2. Descriptive Statistics of Parental Procedural Justice Across PL Groups

\begin{tabular}{lccccc}
\hline & \multicolumn{2}{c}{ Wave I } & \multicolumn{2}{c}{ Wave II } & \\
\cline { 2 - 5 } Group & $M$ & $S D$ & $M$ & $S D$ & $n$ \\
\hline Low-Low & 2.78 & 0.45 & 3.57 & 0.65 & 55 \\
High-Low & 2.83 & 0.41 & 3.73 & 0.52 & 79 \\
Low-High & 2.87 & 0.29 & 3.88 & 0.31 & 127 \\
High-High & 2.92 & 0.21 & 3.88 & 0.33 & 481 \\
\hline
\end{tabular}

\section{Victimization}

We conducted one-way MANOVAs on both waves of the data to see to if the three areas of victimization (home, school, and neighborhood) differed across the four legitimacy-change groups. In both waves, the MANOVAs detected significant differences between groups based on their victimization levels: wave I, $F(3,738)=4.381, p<.01, / 2=.017$; wave II, $F(3,738)=9.235$, $p<.01, / 2=.036$. Overall, those who were in the high PL group in both waves and those who showed increased PL between waves reported lower incidences of victimization compared with the other two groups.

A pairwise comparison with a Bonferroni correction revealed that for wave I, the significant difference in home and neighborhood victimization was between the High-High and the Low-Low groups. For school victimization, the Low-Low group results were significantly different from both the High-High and the Low-High groups. For wave II, the pairwise comparisons revealed that, for home and school victimization, the Low-Low and the High-Low groups were significantly different from the High-High and the Low-High groups. These findings indicate that suffering some form of victimization at home or school coincided with delegitimizing family authorities from one year to the next. Additionally, the High-High group and the Low-Low group differed significantly in neighborhood victimization in wave II.

Overall, for most variables, the group with the highest victimization was the Low-Low PL group, followed by the High-Low PL group. The only exception was that for wave II home victimization, the High-Low group had the highest level, suggesting that suffering some form of recent home victimization was associated with a decline in PL from one year to the next. Descriptive statistics for these findings are provided in Table 3. There are visual representations in Figures 1 and 2.

Finally, a follow-up discriminant analysis on wave I victimization variables revealed that neighborhood victimization $(r=.713)$ was most associated with the difference between groups when compared to school $(r=-.530)$ and home victimization $(r=.189)$. We suggest that this analysis indicates that growing up in a more dangerous neighborhood was a differentiating factor for PL perception change in early adolescence. Discriminant analysis on wave II victimization 
International Journal of Child, Youth and Family Studies (2020) 11(1): 23-45

revealed that all three types of victimization were important to differentiate the groups, but home victimization was the most important $(r=.883)$, followed by school $(r=.672)$, then neighborhood $(r=.364)$. As well, we note that wave II speaks to recent victimization, whereas wave I represents events that have occurred at any point prior to wave I; we therefore suggest that recent home victimization was the primary differentiating variable in the perception-change of PL of preadolescents.

Table 3. Descriptive Statistics of Victimization Across Waves and Legitimacy Groups

\begin{tabular}{|c|c|c|c|c|c|}
\hline Wave & Victimization context & Group & $M$ & $S D$ & $n$ \\
\hline \multirow{12}{*}{$\begin{array}{c}\text { I } \\
(2016)\end{array}$} & \multirow[t]{4}{*}{ Home } & Low-Low & 1.8545 & 1.79936 & 55 \\
\hline & & High-Low & 1.5316 & 1.52614 & 79 \\
\hline & & Low-High & 1.4409 & 1.36075 & 127 \\
\hline & & High-High & 1.2058 & 1.40284 & 481 \\
\hline & \multirow[t]{4}{*}{ School } & Low-Low & 3.2545 & 3.47061 & 55 \\
\hline & & High-Low & 2.4304 & 1.7591 & 79 \\
\hline & & Low-High & 1.8583 & 1.89705 & 127 \\
\hline & & High-High & 2.0042 & 1.8786 & 481 \\
\hline & \multirow[t]{4}{*}{ Neighborhood } & Low-Low & 2.9091 & 2.54786 & 55 \\
\hline & & High-Low & 1.9241 & 2.20589 & 79 \\
\hline & & Low-High & 2.5276 & 2.41959 & 127 \\
\hline & & High-High & 2.0083 & 2.29127 & 481 \\
\hline \multirow{12}{*}{$\begin{array}{c}\text { II } \\
(2017)\end{array}$} & \multirow[t]{4}{*}{ Home } & Low-Low & 1.4909 & 1.91362 & 55 \\
\hline & & High-Low & 1.7848 & 1.74437 & 79 \\
\hline & & Low-High & 0.9921 & 1.19852 & 127 \\
\hline & & High-High & 0.9667 & 1.33967 & 481 \\
\hline & \multirow[t]{4}{*}{ School } & Low-Low & 3.1273 & 2.45745 & 55 \\
\hline & & High-Low & 2.9114 & 2.00761 & 79 \\
\hline & & Low-High & 2.0551 & 2.04438 & 127 \\
\hline & & High-High & 2.0603 & 1.80927 & 481 \\
\hline & \multirow[t]{4}{*}{ Neighborhood } & Low-Low & 2.9273 & 2.98052 & 55 \\
\hline & & High-Low & 2.6203 & 2.68569 & 79 \\
\hline & & Low-High & 2.3622 & 3.04639 & 127 \\
\hline & & High-High & 1.9023 & 2.59744 & 481 \\
\hline
\end{tabular}

Figure 1. Means of Wave I Victimization Levels 
International Journal of Child, Youth and Family Studies (2020) 11(1): 23-45

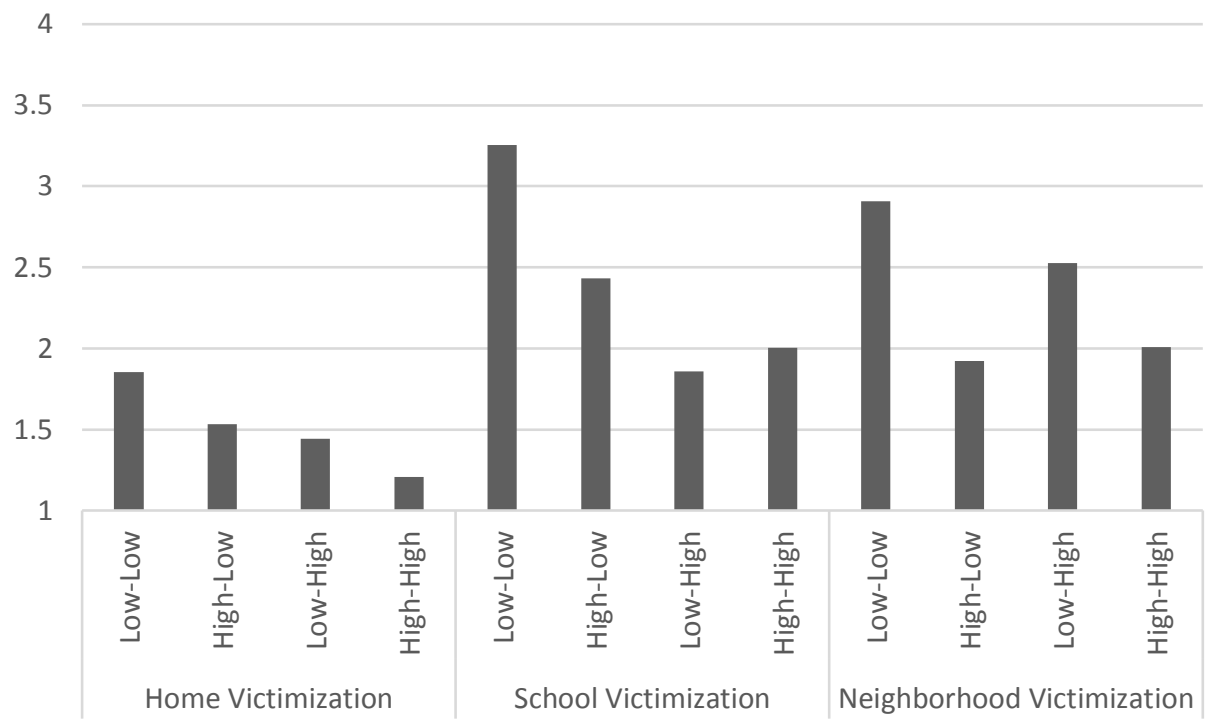

Figure 2. Means of Wave II Victimization Levels

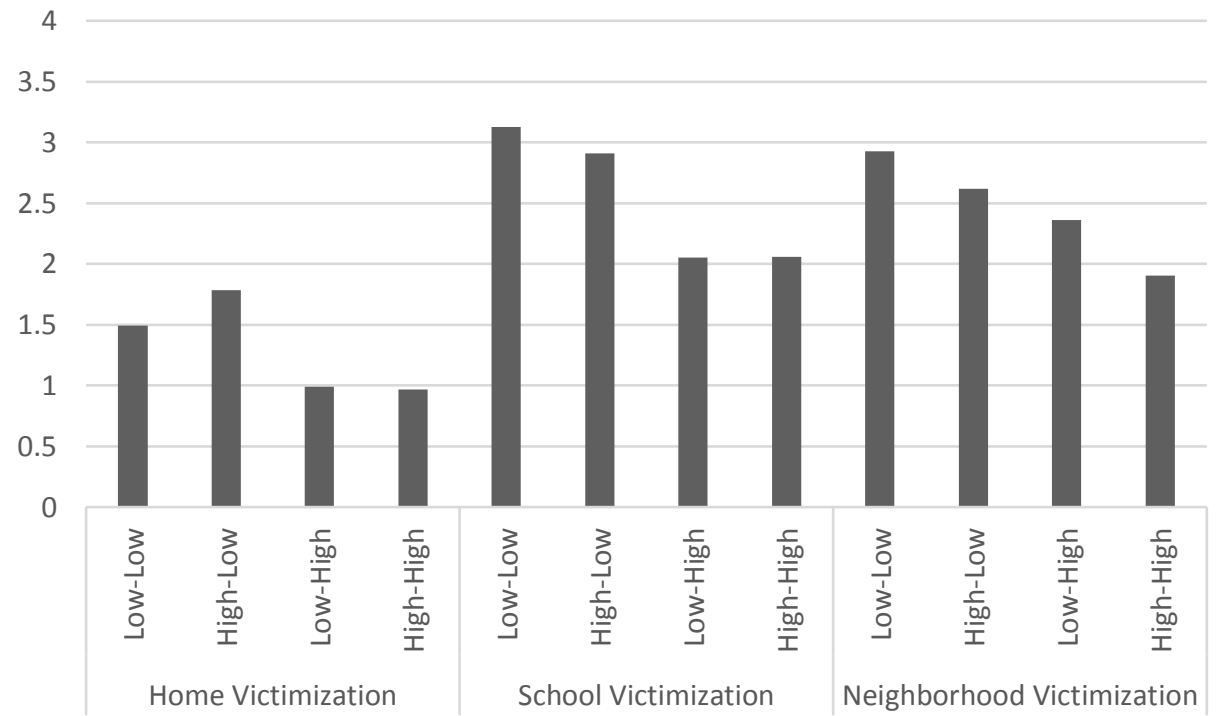

\section{Discussion}

The purpose of the study was to understand whether procedural justice and victimization were important variables in appraising PL perception-change in early adolescence. Consistent with previous research (e.g., Trinkner et al., 2012), parental procedural justice supported the differentiation of perception-change in positive ways (legitimizing parents), while home, school or neighborhood victimization distinguished the delegitimizing groups. 
International Journal of Child, Youth and Family Studies (2020) 11(1): 23-45

\section{Procedural Justice and Parental Legitimacy}

The importance of procedural justice (the perception of whether authorities act in fair and equitable ways) originated with and has been predominant in legal system socialization research (Piquero et al., 2005). In this inquiry, preadolescents' responses concerning PL supported the procedural justice model of legal socialization (Tyler, 2006; Tyler \& Trinkner, 2017). Previous studies indicated that the model of legal socialization is significant to understanding how procedural justice impacts the legitimacy of parental authorities (Darling et al., 2008); our results corroborated this. The findings were also consistent with two previous longitudinal studies (Darling et al., 2007; Smetana et al., 2000), which posited that procedural justice is a critical variable in preadolescents' domain-specific judgements of PL. Notably, the findings further establish that procedural justice plays a decisive role with a younger population.

The results did not support our expectation that PL would decrease from wave I to wave II. Notably, the results demonstrated that PL did not inherently decrease in early adolescence as our data contained a large group $(n=127)$ of preadolescents whose legitimacy of parental authority significantly increased from wave I to wave II. These results were unexpected, as some level of decrease is not only expected but is considered healthy, particularly in terms of personal domains (Darling et al., 2008; Smetana et al., 2000); the decrease is an expected part of the process of individuation. For example, the results from Darling et al.'s (2008) longitudinal study in Chile evidenced a deep decline of belief in PL in early adolescence in the personal domain as these young people negotiated autonomy, while Smetana et al.'s (2000) study with African-American families indicated a decrease in obedience that was attributed to the normative process of individuation.

Our results indicated an increase in PL from wave I to wave II. These variances have several possible explanations: The results of our study may be interpreted from a perspective that focuses on the procedural justice aspect as well as sociocultural issues. Darling and colleagues (2008) interpreted the decreased PL in the personal domain as reflecting the expected increase of adolescent autonomy. The 10 PL issues reflected in our study (see Table 1) feature a combination of autonomy, moral, and safety concerns of young people growing up in São Paulo, a city known for its high crime rate (de Melo et al., 2016). Perhaps because of safety concerns, as the young people mature in São Paulo and become cognizant of security (prudential) issues, they perceive that their desire for increased autonomy is directly opposed to legitimate security concerns; this could contribute to their perception of parental authority as fair even in personal domains. Our findings concur with Darling et al.'s (2005) assertion that PL is influenced by adolescent autonomy, which is a complex, multidimensional disposition influenced by sociocultural issues. Similarly, a more recent inquiry on PL with Iraqi, Syrian, and Palestinian adolescent refugees (Smetana et al., 2015) suggested the participants had decreased PL over personal issues but sustained PL on prudential ones. 
International Journal of Child, Youth and Family Studies (2020) 11(1): 23-45

While our results confirmed that procedural justice was of considerable importance to differentiating PL perception-change even in the younger population and highlighted that PL may actually rise over time rather than decrease, the results also made salient that victimization in the three contexts of home, school, and neighborhood can be a powerful negative influence, which we identify as victimization jeopardy.

\section{Victimization Jeopardy}

The second focus of our analysis was the impact of victimization (which encompasses both being a victim and witnessing violence) on PL. Consistent with what we hypothesized, victimization significantly influenced PL. The results revealed that victimization at all three levels (home, school, and neighborhood) significantly differentiated the legitimacy group. While the findings may seem predictable and common sense, they provide us with previously lacking empirical evidence.

Children suffer more victimization than adults, and the home environment is not only frequently the source of victimization for children (Artz et al., 2014), but also one of the places where children are most likely to witness violence (Finkelhor \& Dzuiba-Leatherman, 1994). In this inquiry, recent (wave II) within-family exposures to victimization emerged as the most important variable to differentiate PL perception-change. If participants reported being victimized at home in the past year, that was the single most important variable to differentiate between PL groups.

School victimization was also central to receding PL in both waves. Suffering victimization at school served to undermine preadolescents' beliefs about the legitimacy of parents. The results provided an example of the outcome of the intersections between two microsystems, reflecting Bronfenbrenner's (1977) mesosystem in the adolescents' socialization process. The current research also added a new component to a previous study (Hughes et al., 2015), which revealed that feeling unsafe at school impacted mental health, truancy, and academic success. Now, it appears that it may also impact PL.

Neighborhood victimization (seeing people selling drugs, being robbed, or carrying guns [without being a policeman], or hearing a gunshot) had a similar mesosystem effect, as those who suffered the most neighborhood victimization were in the lower PL threshold groups. This finding highlights the potential cascading effect of victimization, revealing that the experience of being victimized may impact how preadolescents perceive and relate to authorities.

While it is foreseeable that home victimization would decrease PL, why would victimization at school or in the neighborhood also diminish it? One possibility is that preadolescents may perceive victimization at home, school, or neighborhood as neglect or inability to protect, resulting in decreased PL. Parents may be unaware of victimization at school or in the neighborhood, and may be experiencing a loss of PL without knowing why this is happening. When preadolescents move away from or reject PL at such a young age, this may open a 
International Journal of Child, Youth and Family Studies (2020) 11(1): 23-45

socialization void and reinforces Darling et al.'s (2007) finding that adolescents play an active role in the development of their own legitimacy beliefs.

Our results expand previous findings that both direct and indirect victimization negatively alter children's perception of PL. Johnson et al.'s (2002) research revealed that victimization at home and in the neighborhood, whether direct or witnessed, was a significant predictor of aggression and depression. Subsequently, a comprehensive national survey of children's exposure to violence (Hamby et al., 2011) confirmed that such exposure distressed children and is related to a multitude of mental health issues in both childhood and later life. Our results expand the focus from the clinical trauma of victimization to the legal socialization of the general population. These findings further indicate that preadolescents delegitimize authorities even when the victimization exposure did not happen at home. Thus, our study provides a basis for us to theorize that any form of victimization could propel preadolescents to delegitimize authorities, making PL vulnerable (victimization jeopardy).

\section{Conclusion}

\section{Implications}

The implications for parents are multifaceted. While many parents see the decline of PL as unavoidable, our results indicate that the decline may depend more on the lack of procedural justice, which is within parental control. If parents use the hopeful and evidence-based lenses provided by these results to proactively and intentionally implement strong procedural justice practices (i.e., establish effective disciplinary practices with clear, reasonable, and consistent rules), they can prevent or minimize this tendency. The findings from this study could aid school counselors, social workers, and psychologists, among others, in the dissemination of parenting styles that include procedural justice as a socialization practice. This inquiry reveals the importance of understanding that various levels of victimization in multiple contexts are also, tragically, a common variable in child and adolescent development. These findings suggest the centrality of addressing victimization and confirm the importance of a more comprehensive approach to broader domains of victimization.

\section{Limitations}

Like many other inquiries on adolescents' beliefs about PL, this study of Brazilian preadolescents relies on data drawn solely from preadolescents' self-reports. While this could be a concern as it does not reflect parental perspectives, it is the preadolescents' own perceptions that influence their decision whether to comply with parental authority, which is what the researchers are studying. In addition, since the data results reflect a sample from the largest Brazilian city, the applicability and generalization of findings to other populations will vary. However, the sample was socially and racially diverse, and findings are embedded in published international scholarship providing a backdrop from which the findings can be interpreted. The information provided allows the reader to conclude whether the findings are transferable to a particular population. 
International Journal of Child, Youth and Family Studies (2020) 11(1): 23-45

\section{Future Research}

The implications of the findings regarding victimization and the premature weakening of PL require further investigation. In addition, a mixed-method study could provide more comprehensive data with which to address the connection of school and neighborhood victimization and contraction of PL and expose who or what is being substituted for the parents in this influential role. Future research could also take parental factors into consideration in order to fully understand the dynamics of victimization.

\section{Funding}

Data used in this study were taken from the São Paulo Legal Socialization Study, which was funded by the São Paulo Research Foundation from the 2013-2018 Research, Innovation and Dissemination Centers (RIDCs) grant (No. 2013/07923-7). 
International Journal of Child, Youth and Family Studies (2020) 11(1): 23-45

\section{References}

Aquilino, W. S., \& Supple, A. J. (2001). Long-term effects of parenting practices during adolescence on well-being outcomes in young adulthood. Journal of Family Issues, 22(3), 289-308. doi:10.1177/019251301022003002

Artz, S., Jackson, M. A., Rossiter, K. R., Nijdam-Jones, A., Géczy, I., \& Porteous, S. (2014). A comprehensive review of the literature on the impact of exposure to intimate partner violence for children and youth. International Journal of Child, Youth and Family Studies, 5(4), 493-587. doi:10.18357/ijcyfs54201413274

Assis, S. G., Oliveira, R. V. C., Pires, T. O., Avanci, J. Q., \& Pesce, R. P. (2013). Family, school and community violence and problem behavior in childhood: Results from a longitudinal study in Brazil. Paediatrics Today, 9(1), 36-48. doi:10.5457/p2005-114.59

Benchaya, M. C., Bisch, N. K., Moreira, T. C., Ferigolo, M., \& Barros, H. (2011). Nonauthoritative parents and impact on drug use: The perception of adolescent children. Jornal de Pediatria (Rio de Janeiro), 87, 238-244. doi:10.2223/JPED.2089

Berg, M. (2011). The overlap between violent offending and violent victimization: Assessing the evidence and explanations. In M. DeLisi \& P. Conis (Eds.), Violent offenders: Theory, research, policy, and practice ( $3^{\text {rd }}$ edition, pp. 13-27). Jones and Bartlett.

Blader, S. L., \& Tyler, T. R. (2003). A four-component model of procedural justice: Defining the meaning of a "fair" process. Personality and Social Psychology Bulletin, 29(6), 747-758. doi: $10.1177 / 0146167203029006007$

Boney-McCoy, S., \& Finkelhor, D. (1995). Psychosocial sequelae of violent victimization in a national youth sample. Journal of Consulting \& Clinical Psychology, 63(5), 726-736. doi:10.1037//0022-006x.63.5.726

Brazilian National Health Council. (2012). Resolution 466/2012. Retrieved from https://conselho.saude.gov.br/resolucoes/2012/466_english.pdf

Bronfenbrenner, U. (1977). Toward an experimental ecology of human development. American Psychologist, 32(7), 513-531. doi:10.1037/0003-066X.32.7.513

Cardia, N. (2012). Pesquisa nacional, por amostragem domiciliar, sobre atitudes, normas culturais e valores em relação à violação de direitos humanos e violência [National research by domestic sample about attitudes, cultural norms, and values related to the violation of human rights and violence]. São Paulo, Brazil: Center for the Study of Violence at the University of São Paulo. Retrieved from http://nevusp.org/wpcontent/uploads/2015/01/down264.pdf 
International Journal of Child, Youth and Family Studies (2020) 11(1): 23-45

Cashmore, J. (2002). Promoting the participation of children and young people in care. Child Abuse \& Neglect, 26(8), 837-847. doi:10.1016/s0145-2134(02)00353-8

Center for the Study of Violence at the University of São Paulo. (2016/2017). 4th Report: São Paulo Legal Socialization Study. Author. Retrieved from https://drive.google.com/file/d/0B73LkK8thVQSQld4REt1TUFTb0k/view

Chang, H., \& Shaw, D. S. (2015). The emergence of parent-child coercive processes in toddlerhood. Child Psychiatry \& Human Development, 47(2), 226-235. doi:10.1007/s10578-015-0559-6

Chang, J. J., Chen, J. J., \& Brownson, R. C. (2003). The role of repeat victimization in adolescent delinquent behaviors and recidivism. Journal of Adolescent Health, 32(4), 272280. doi:10.1016/s1054-139x(02)00564-5

Darling, N., Cumsille, P., \& Martínez, M. L. (2007). Adolescents' as active agents in the socialization process: Legitimacy of parental authority and obligation to obey as predictors of obedience. Journal of Adolescence, 30(2), 297-311. doi:10.1016/j.adolescence.2006.03.003

Darling, N., Cumsille, P., \& Martinez, M. L. (2008). Individual differences in adolescents' beliefs about the legitimacy of parental authority and their own obligation to obey: A longitudinal investigation. Child Development, 79(4), 1103-1118. doi:10.1111/j.1467$\underline{\text { 8624.2008.01178.x }}$

Darling, N., Cumsille, P., \& Peña-Alampay, L. (2005). Rules, legitimacy of parental authority, and obligation to obey in Chile, the Philippines, and the United States. In J. Smetana (Ed.), New directions for child and adolescent development. Changing boundaries of parental authority during adolescence (pp. 47-60). Jossey-Bass.

de Albuquerque Williams, L. C., D’Affonseca, S. M., Correia, T. A., \& de Albuquerque, P. P. (2011). Efeitos a longo prazo de vitimização na escola [Long term effects of school victimization]. Gerais: Revista Interinstitucional de Psicologia, 4(2), 187-199. Retrieved from http://pepsic.bvsalud.org/scielo.php?script=sci_arttext\&pid=S1983$\underline{82202011000200002}$

de Melo, S. N., Andresen, M. A., \& Matias, L. F. (2016). Geography of crime in a Brazilian context: An application of social disorganization theory. Urban Geography, 38(10), 15501572. doi:10.1080/02723638.2016.1255920

Dishion, T. J., \& McMahon, R. J. (1998). Parental monitoring and the prevention of child and adolescent problem behavior: A conceptual and empirical formulation. Clinical Child and Family Psychology Review, 1(61), 61-75. doi:10.1023/A:1021800432380 
International Journal of Child, Youth and Family Studies (2020) 11(1): 23-45

Durkin, A. (2016). The development of a preference for procedural justice (Unpublished bachelor's thesis). Yale University, New Haven, CT. Retrieved from http://cogsci.yale.edu/sites/default/files/files/Thesis2016Durkin.pdf

Fagan, J., \& Tyler, T. R. (2005). Legal socialization of children and adolescents. Social Justice Research, 18(3), 217-242. doi:10.1007/s11211-005-6823-3

Finkelhor, D., \& Dzuiba-Leatherman, J. (1994). Victimization of children. American Psychologist, 49(3), 173-183. doi:10.1037/0003-066X.49.3.173

Finkelhor, D., Ormrod, R., Turner, H., \& Hamby, S. L. (2005). The victimization of children and youth: A comprehensive, national survey. Child Maltreatment, 10(1), 5-25. doi: $10.1177 / 1077559504271287$

Flannery, D. J., Singer, M., Williams, L., \& Castro, P. (1998). Adolescent violence exposure and victimization at home: Coping and psychological trauma symptoms. International Review of Victimology, 6(1), 29-48. doi:10.1177/026975809800600103

Gibson, C. L. (2012). Unpacking the influence of neighborhood context and antisocial propensity on violent victimization of children and adolescents in Chicago: A final report submitted to the National Institute of Justice. Retrieved from https://www.ncjrs.gov/pdffiles1/nij/grants/237731.pdf

Gold, L. J., Darley, J. M., Hilton, J. L., \& Zanna, M. P. (1984). Children's perceptions of procedural justice. Child Development, 55(5), 1752-1759. doi:10.2307/1129922

Hamby, S., Finkelhor, D., Turner, H., \& Ormrod, R. (2011). Children's exposure to intimate partner violence and other family violence. Juvenile Justice Bulletin, October. Retrieved from https://www.ncjrs.gov/pdffiles1/ojjdp/232272.pdf

Hartinger-Saunders, R. M., Rittner, B., Wieczorek, W., Nochajski, T., Rine, C. M., \& Welte, J. (2011). Victimization, psychological distress and subsequent offending among youth. Children and Youth Services Review, 33(11), 2375-2385. doi:10.1016/j.childyouth.2011.08.009

Hicks, A. J., \& Lawrence, J. A. (1993). Children's criteria for procedural justice: Developing a young people's procedural justice scale. Social Justice Research, 6(2), 163--182. doi:10.1007/bf01048475

Hughes, M. R., Gaines, J. S., \& Pryor, D. W. (2015). Staying away from school: Adolescents who miss school due to feeling unsafe. Youth Violence and Juvenile Justice, 13(3), 270290. doi:10.1177/1541204014538067

Instituto Nacional de Estudos e Pesquisas Educacionais Anisio Teixeira. (2014). Censo escolar [School census; Data file]. Retrieved from http://inep.gov.br/microdados 
International Journal of Child, Youth and Family Studies (2020) 11(1): 23-45

Jackson, J., Bradford, B., Hough, M., Myhill, A., Quinton, P., \& Tyler, T. R. (2012). Why do people comply with the law? Legitimacy and the influence of legal institutions. British Journal of Criminology, 52(6), 1051-1071. doi:10.1093/bjc/azs032

Johnson, R. M., Kotch, J. B., Catellier, D. J., Winsor, J. R., Dufort, V., Hunter, W., \& AmayaJackson, L. (2002). Adverse behavioral and emotional outcomes from child abuse and witnessed violence. Child Maltreatment, 7(3), 179-186. doi:10.1177/1077559502007003001

Kerr, M., Stattin, H., \& Trost, K. (1999). To know you is to trust you: Parents trust is rooted in child disclosure of information. Journal of Adolescence, 22(6), 737-752. doi:10.1006/jado.1999.0266

Kliewer, W., Murrelle, L., Mejia, R., Torres, de G. Y., \& Angold, A. (2001). Exposure to violence against a family member and internalizing symptoms in Colombian adolescent: The protective effects of family support. Journal of Consulting and Clinical Psychology, 69(6), 971-982. doi:10.1037/0022-006X.69.6.971

Lauritsen, J. L., \& Laub, J. H. (2007). Understanding the link between victimization and offending: New reflections on an old idea. In M. Hough, \& M. Maxfield (Eds.), Surveying crime in the $21^{\text {st }}$ century (Vol. 22, pp. 55-76). Criminal Justice Press.

Lessne, D., Cidade, M., Gerke, A., Roland, K., \& Sinclair, M. (2016). Student victimization in U.S. schools: Results from the 2013 school crime supplement to the national crime victimization survey (Stats in Brief, NCES 2016-145). Retrieved from https://nces.ed.gov/pubs2016/2016145.pdf

Medina, J. C., \& Rodrigues, H. (2019). The effects of victimization and fear of crime on the legal socialization of young adolescents in São Paulo, Brazil. International Journal of Offender Therapy and Comparative Criminology, 63(8), 1148-1174. doi: $10.1177 / 0306624 X 18818810$

Milnitsky-Sapiro, C., Turiel, E., \& Nucci, L. (2006). Brazilian adolescents' conceptions of autonomy and parental authority. Cognitive Development, 21(3), 317-331. doi:10.1016/j.cogdev.2006.01.001

Moffitt, T. E., \& Caspi, A. (1998). Annotation: Implications of violence between intimate partners for child psychologists and psychiatrists. Journal of Child Psychology and Psychiatry, 39(2), 137-144. doi:10.1111/1469-7610.00308

Truman, J. L., \& Morgan, R. E. (2016). Criminal victimization, 2015. (Bulletin of the Bureau of Justice Statistics, NCJ 250180). Retrieved from https://www.bjs.gov/content/pub/pdf/cv15.pdf 
International Journal of Child, Youth and Family Studies (2020) 11(1): 23-45

Mrug, S., \& Windle, M. (2010). Prospective effects of violence exposure across multiple contexts on early adolescents' internalizing and externalizing problems. Journal of Child Psychology and Psychiatry, 51(8), 953-961. doi:10.1111/j.1469-7610.2010.02222.x

Nicholas, K. B., \& Rasmussen, E. H. (2006). Childhood abusive and supportive experiences, inter-parental violence, and parental alcohol use: Prediction of young adult depressive symptoms and aggression. Journal of Family Violence, 21(1), 43-61. doi:10.1007/s10896$\underline{\text { 005-9001-3 }}$

Nofziger, S., \& Kurtz, D. (2005). Violent lives: A lifestyle model linking exposure to violence to juvenile violent offending. Journal of Research in Crime and Delinquency, 42(1), 3-26. doi:10.1177/0022427803262061

Nucci, L. P., Guerra, N., \& Lee, J. (1991). Adolescent judgments of the personal, prudential, and normative aspects of drug usage. Developmental Psychology, 27(5), 841-848. doi:10.1037/0012-1649.27.5.841

Pennington, L. (2015). A case study approach to procedural justice: Parents' views in two juvenile delinquency courts in the United States. British Journal of Criminology, 55(5), 901-920. doi:10.1093/bjc/azu109

Piquero, A. R., Fagan, J., Mulvey, E. P., Steinberg, L., \& Odgers, C. (2005). Developmental trajectories of legal socialization among serious adolescent offenders. Journal of Criminal Law and Criminology, 96(1), 267-298. doi:0091-4169/05/9601-0267

Rodrigues, H., \& Gomes, A. M. M. (2017). Socialização legal e perfis de pré-adolescentes em São Paulo: Uma análise de correspondência [Legal socialization and profiles of early adolescents in São Paulo: An analysis of correspondence]. Crítica e Sociedade, 7(2), 181206. Retrieved from http://www.seer.ufu.br/index.php/criticasociedade/article/view/40979

Rodrigues, H., Gomes, A. M. M., de Oliveira, R. T., Piccirillo, D., \& de Brito, R. C. (2017). Socialização legal de crianças e adolescentes: Revisão da literatura e desafios de pesquisa [Legal socialization of children and adolescents: Literature review and research challenges]. Plural - Revista de Ciências Sociais. 24(1), 105-123. doi:10.11606/issn.21768099.pcso.2017.127330

Rosenbaum, D. P., Schuck, A. M., Costello, S. K., Hawkins, D. F., \& Ring, M. K. (2005). Attitudes toward the police: The effects of direct and vicarious experience. Police Quarterly, 8(3), 343-365. doi:10.1177/1098611104271085

Shaffer, J. N., \& Ruback, R. B. (2002). Violent victimization as a risk factor for violent offending among juveniles. Juvenile Justice Bulletin, December. Retrieved from https://www.ncjrs.gov/pdffiles1/ojjdp/195737.pdf 
International Journal of Child, Youth and Family Studies (2020) 11(1): 23-45

Sharkey, P. T., Tirado-Shaver, N., Papachristos, A. V., \& Raver, C. C. (2012). The effect of local violence on children's attention and impulse control. American Journal of Public Health, 102(12), 2287-2293. doi:10.2105/AJPH.2012.300789

Skinner, C. J. (2016). Probability Proportional to Size (PPS) sampling. Wiley StatsRef: Statistics Reference Online, 1-5. doi:10.1002/9781118445112.stat03346.pub2

Smetana, J. G., Abernethy, A., \& Harris, A. (2000). Adolescent-parent interactions in middleclass African American families: Longitudinal change and contextual variations. Journal of Family Psychology, 14(3), 458-474. doi:10.1037//0893-3200.14.3.458

Smetana, J., Ahmad, I., \& Wray-Lake, L. (2015). Iraqi, Syrian, and Palestinian refugee adolescents' beliefs about parental authority legitimacy and its correlates. Child Development, 86(6), 2017-2033. doi:10.1111/cdev.12457

Smetana, J., Crean, H. F., \& Campione-Barr, N. (2005). Adolescents and parents changing conceptions of parental authority. New Directions for Child and Adolescent Development, 2005(108), 31-46. doi:10.1002/cd.126

Smetana, J. G., \& Daddis, C. (2002). Domain-specific antecedents of parental psychological control and monitoring: The role of parenting beliefs and practices. Child Development, 73(2), 563-580. doi:10.1111/1467-8624.00424

Smetana, J. G., \& Metzger, A. (2005). Family and religious antecedents of civic involvement in middle class African American late adolescents. Journal of Research on Adolescence, 15(3), 325-352. doi:10.1111/j.1532-7795.2005.00099.x

Smetana, J. G., Yau, J., \& Hanson, S. (1991). Conflict resolution in families with adolescents. Journal of Research on Adolescence, 1(2), 189-206. doi:10.1207/s15327795jra0102_5

Sunshine, J., \& Tyler, T. R. (2003). The role of procedural justice and legitimacy in shaping public support for policing. Law \& Society Review, 37(3), 513-548. Retrieved from https://www.jstor.org/stable/1555077

Tapp, J. L. (1991). The geography of legal socialization: Scientific and social markers. Droit et Sociètè, 19(1), 331-358.

Tisak, M. S., Tisak, J., \& Rogers, M. J. (1994). Adolescents' reasoning about authority and friendship relations in the context of drug usage. Journal of Adolescence, 17(3), 265-282. doi:10.1006/jado.1994.1025

Thomas, K., Rodrigues, H., Gomes, A. M. M., de Oliveira, R. T., Piccirillo, D., \& de Brito, R. C. (2018). Parental legitimacy, procedural justice and adolescent compliance with parental rules among Brazilian preadolescents. International Journal of Child, Youth, and Family Studies, 9(3), 21-46. doi:10.18357/ijcyfs93201818275 
International Journal of Child, Youth and Family Studies (2020) 11(1): 23-45

Trinkner, R., \& Cohn, E. S. (2014). Putting the "social" back in legal socialization: Procedural justice, legitimacy, and cynicism in legal and nonlegal authorities. Law and Human Behavior, 38(6), 602-617. doi:10.1037/lhb0000107

Trinkner, R., Cohn, E. S., Rebellon, C. J., \& Van Gundy, K. (2012). Don’t trust anyone over 30: Parental legitimacy as a mediator between parenting style and changes in delinquent behavior over time. Journal of Adolescence, 35(1), 119-132. doi:10.1016/j.adolescence.2011.05.003

Trinkner, R., Jackson, J., \& Tyler, T. R. (2017). Bounded authority: Expanding 'appropriate' police behavior beyond procedural justice (August 22, 2017). doi:10.2139/ssrn.2846659

Trinkner, R., Rodrigues, H., Piccirillo, D., Gifford, F. E., \& Gomes, A. M. M. (2019). Legal socialisation in Brazil: Examining the generalizability of the procedural justice model. International Journal of Comparative and Applied Criminal Justice. Online publication. doi:10.1080/01924036.2019.1587710

Turner, H. A., Finkelhor, D., Ormrod, R., Hamby, S., Leeb, R. T., Mercy, J. A., \& Holt, M. (2012). Family context, victimization, and child trauma symptoms: Variations in safe, stable, and nurturing relationships during early and middle childhood. American Journal of Orthopsychiatry, 82(2), 209-219. doi:10.1111/j.1939-0025.2012.01147.x

Tyler, T. R. (2003). Procedural justice, legitimacy, and the effective rule of law. Crime and Justice, 30, 283-357. doi:10.1086/652233

Tyler, T. R. (2006). Why people obey the law: Procedural justice, legitimacy, and compliance. Princeton University Press.

Tyler, T. R. (2011). Why people cooperate. Princeton, NJ: Princeton University Press.

Tyler, T. R., \& Blader, S. L. (2003). The group engagement model: Procedural justice, social identity, and cooperative behavior. Personality and Social Psychology Review, 7, 349-361. doi:10.1207/S15327957PSPR0704_07

Tyler, T., Fagan, J., \& Geller, A. (2014). Street stops and police legitimacy: Teachable moments in young urban men's legal socialization. Journal of Empirical Legal Studies, 11(4), 751785. doi:10.1111/jels.12055

Tyler, T. R., \& Trinkner, R. (2017). Why children follow rules: Legal socialization and the development of legitimacy. Oxford University Press.

Wilson, H. W., Stover, C. S., \& Berkowitz, S. J. (2009). Research review: The relationship between childhood violence exposure and juvenile antisocial behavior: a meta-analytic review. Journal of Child Psychology and Psychiatry, 50(7), 769-779. doi:10.1111/j.1469$\underline{7610.2008 .01974 . x}$ 